\title{
Interventions Targeting Smoking Cessation for Patients with Chronic Pain: An
}

\section{Evidence synthesis}

Bruno T Saragiotto ${ }^{1,2,3}$, Steven J Kamper ${ }^{3,4}$, Rebecca Hodder ${ }^{1,3}$, Priscilla V Silva ${ }^{1,3,5}$, Luke Wolfenden $^{1,5}$, Hopin Lee ${ }^{1,3,6}$, Vinicius C Oliveira ${ }^{7}$, Emma Robson ${ }^{1,3,5}$, John Wiggers ${ }^{1,5}$, Christopher M Williams $1,3,5$

${ }^{1}$ School of Medicine and Public Health, Hunter Medical Research Institute, University of Newcastle, Newcastle, Australia.

${ }^{2}$ Masters and Doctoral Program in Physical Therapy, Universidade Cidade de Sao Paulo, Sao Paulo, Brazil.

${ }^{3}$ Centre for Pain, Health and Lifestyle.

${ }^{4}$ The University of Sydney, School of Public Health, Australia.

${ }^{5}$ Hunter New England Population Health, Hunter New England Local Health District, Wallsend, Australia.

${ }^{6}$ Centre for Statistics in Medicine, Rehabilitation Research in Oxford, Nuffield Department of Orthopaedics Rheumatology and Musculoskeletal Sciences, University of Oxford, UK.

${ }^{7}$ Postgraduate Program in Rehabilitation and Functional Performance, Universidade Federal dos Vales do Jequitinhonha e Mucuri, Diamantina, Brazil. 


\begin{abstract}
Introduction: Smoking is a risk factor for chronic pain conditions. Epidemiological evidence suggests that smoking cessation may be an important treatment target in people with chronic pain. The aim of this study was to examine the effectiveness of smoking cessation interventions in people with chronic pain.
\end{abstract}

Methods: We systematically searched for clinical trials investigating the effectiveness of smoking cessation interventions for people with chronic pain, compared to any control comparator. Primary outcomes were pain and physical function. Secondary outcomes were smoking status, quality of life, psychological and cognitive function, and adverse events. We assessed risk of bias using the Cochrane Risk of Bias criteria, and the quality of evidence with GRADE.

Results: Searches retrieved 3,845 records and identified two trials for inclusion (total $n=99$ participants). There was low quality evidence of no effect of smoking cessation programs on pain and very low quality evidence of no effect on function at short term follow-up. There was conflicting evidence on the effect of smoking cessation interventions for changing the smoking status, and number of cigarettes consumed per day. There was no effect on depression and anxiety.

Conclusion: Current evidence does not indicate clinically important effects of smoking cessation interventions in people with chronic pain. There is a need for high quality trials in this area.

Implications: Our review highlights an important evidence gap. We found only two studies investigating smoking cessation programs for chronic pain conditions providing very low to low quality evidence. 


\section{INTRODUCTION}

Chronic pain affects up to one third of the adult population and is responsible for an enormous societal burden. ${ }^{1}$ The most common causes of chronic pain are musculoskeletal disorders of the back, neck and upper limbs; as well as osteoarthritis of the knee and hip. ${ }^{2}$ In the recent global burden of disease study, musculoskeletal pain accounted for more than $20 \%$ of years lived with disability in the population. ${ }^{2}$ Chronic pain disorders also impose enormous costs to countries due to high levels of health care use, morbidity and work absenteeism. $^{3}$

Smoking is one health behaviour consistently associated with chronic pain, suggesting it is an important risk factor for many chronic pain conditions, including back pain, sciatica and rheumatoid arthritis. ${ }^{4-6}$ There are some possible mechanisms to explain the association between smoking and chronic pain conditions, but the most common may be related to the malnutrition of cells by carboxy-hemoglobin-induced anoxia and increased sensitivity of pain receptors in the brain. ${ }^{7-9}$ There is evidence that those with chronic pain who are smokers present with more severe symptoms, have poorer treatment outcomes, and more symptoms of depression compared to non-smokers. ${ }^{10-12}$ As such, smoking cessation has been suggested as a potentially important treatment target in people with chronic pain. ${ }^{13,14}$ Despite this potential, to our knowledge there is no systematic reviews to synthesise the state of this evidence. The aim of this systematic review is to examine the effectiveness of smoking cessation interventions compared to active or inactive controls on improving pain and function in people with chronic pain at short, intermediate, and long-term follow-up.

\section{METHODS}

This systematic review is reported according to PRISMA recommendations, ${ }^{15}$ and the protocol was prospectively registered on PROSPERO (2017: CRD42017073643).

\section{Data Sources and Searches}

We searched the following databases from inception to June 2018: Cochrane Central Register of Controlled Trials (CENTRAL) in the Cochrane Library, MEDLINE, MEDLINE in Process, EMBASE, CINAHL, AMED, and PsycINFO. The reference lists of included studies were searched. We did not place any restriction to language of publication. We used a combination of keywords to construct the search strategy (supplementary file 1). Two 
independent reviewers screened titles, abstracts, and full text articles for inclusion (BS, RH/PS). Disagreements were resolved by discussion and where required with input from a third reviewer (SK).

\section{Study Selection}

We considered randomised and quasi-randomised (e.g. allocation by hospital record number, birth date, or alternation) controlled trials. To be eligible, trials had to include participants, who were current smokers, with chronic pain (pain lasting $\geq 3$ months) of any location verified by clinical or radiological diagnosis. There were no restrictions on participant age or care settings. We excluded trials that included participants with serious underlying causes of their pain (i.e. fracture, infectious disease, cancer).

We included trials that tested an intervention with the intent of reducing smoking behaviour (e.g. pharmacological, physical activity programs, behavioural or psychological treatments, acupuncture, or a combination of these). Interventions could be single or multicomponent. We considered all trials with a comparison group that received any active or inactive control intervention (e.g. placebo, another intervention, usual care) or no intervention (e.g. wait-list controls).

Primary outcomes were pain intensity or physical function related to chronic pain, measured using a valid instrument. The secondary outcomes were: a measure of smoking status (e.g. sustained smoking cessation, abstinence, self-reported quit data, percentage abstinent in the intervention and control group); quality of life; psychological function (e.g. depression, anxiety, fear avoidance, coping, self-efficacy); participant adherence, participant satisfaction with the treatment; and adverse events.

\section{Data Extraction and Quality Assessment}

Data extraction and quality assessment was completed independently by two reviewers (BS and PS) and any disagreements were resolved by discussion and, where required with input from a third review author (SK). We used a standardised data extraction form to extract information regarding study characteristics (design, study population, inclusion/exclusion criteria, intervention and comparison groups), and primary and secondary outcomes. We contacted the authors, and received additional data regarding the outcomes pain, depression and anxiety for one trial. ${ }^{15}$ 
We assessed risk of bias using the Cochrane Back and Neck Review Group 12-item criteria. ${ }^{16}$ We categorised trials as 'low risk' (at least six of the 12 criteria met) or 'high risk' (fewer than six criteria met). The quality of evidence was rated for each comparison with the GRADE system based on four domains: 1) study design and risk of bias, downgraded if $>25 \%$ of the participants were from studies with a high risk of bias; 2) inconsistency of results, downgraded if significant heterogeneity was apparent on visual inspection or $\mathrm{I}^{2}$ statistics $>50 \% ; 3$ ) indirectness (generalisability of the findings), downgraded if $>50 \%$ of the participants were outside the target group); and 4) imprecision, downgraded if fewer than 400 participants were included in the comparison for continuous data and there were fewer than 300 events for dichotomous data. We did not downgrade for publication bias due to the small number of studies included. The quality of evidence was rated as high, moderate, low or very low.

\section{Data Synthesis and Analysis}

We conducted separate random-effects meta-analyses for the following follow-up points: short (less than three months after randomisation), intermediate (at least three months but less than 12 months) and long-term (12 months or more). Heterogeneity was analysed by visual inspection of the forest plots and the $\mathrm{I}^{2}$ test for comparisons including more than one study. We expressed pooled effects of continuous variables as mean differences (MD) and 95\% confidence interval (CI) if the same outcome measure were used, and standardised mean differences (SMD) if different measures were used. For dichotomous outcomes, we calculated risk ratios (RR) with 95\% CI. In the event that SMDs were statistically significant, we planned to calculate the MD in units of a common measure for that construct to interpret clinical relevance. Effect sizes were categorised in three levels: small (MD < 10\% of the scale), medium (MD $10 \%$ to $20 \%$ of the scale), or large (MD > $20 \%$ of the scale). ${ }^{22} \mathrm{We}$ deemed an effect to be clinically important when the effect size was at least medium $(\geq 10 \%$ of the scale). ${ }^{17}$ We prioritised intention-to-treat analyses over per-protocol analyses if available.

We planned to perform a sensitivity analysis to explore the influence of risk of bias on pooled treatment effects of the primary outcomes, and subgroup analyses for the type of interventions. However, this was not possible due to the small number of included studies.

\section{RESULTS}


The searches retrieved 3,845 records, after screening of titles, abstracts, and full text articles, we included 2 randomised controlled trials ( $n=99$ participants) (supplementary file 2) ${ }^{18,19}$. One trial included patients with non-cancer pain $^{19}$ and the other included patients with Rheumatoid Arthritis. ${ }^{18}$ Most patients were women (69\%), mean age was 49.6 years (SD 12.6). One trial included a 3 -month tailored smoking cessation program, and the other trial included a 7-session (3 week), cognitive behavioural smoking abstinence program (Table 1). Control groups were; standard smoking cessation advice, ${ }^{18}$ and a 1-hour smoking abstinence intervention. ${ }^{19}$

Both trials were considered to have low risk of bias (supplementary file 3). However, allocation concealment was unclear for one trial ${ }^{18}$ and blinding of patients or care provider was not possible for both trials. Neither trial reported information on co-interventions. Registered protocols were available for both trials.

\section{Primary outcomes}

Meta-analysis of the two studies showed there was low quality evidence of no significant effect of the smoking cessation programs on pain at short term (SMD - $0.33,95 \%$ CI -0.79 to $0.12,2$ trials, $\mathrm{I}^{2}=0 \%$ ). Based on a single study, there was low quality evidence of no significant effect of the smoking cessation programs on pain at intermediate term (MD -0.27, -2.06 to 1.52$)$ and for the outcome function at short term (MD -3.3, 95\% CI -11.73 to 5.13) (Table 2).

\section{Secondary outcomes}

There was very low-quality evidence of no difference in smoking status between groups at short term (RR $0.78,95 \%$ CI 0.60 to 1.01 ) based on one single study; however there was lowquality evidence from meta-analysis of a significant reduction in smoking status at intermediate term (RR $0.83,0.70$ to $0.98, \mathrm{I}^{2}=0 \%$ ) based on two studies. The mean number of cigarettes consumed per day was significantly less in the smoking cessation group at short term (MD $-6.90,-12.07$ to -1.73 ), but there is very low-quality evidence that there was no difference at intermediate term, both based on one single study. Meta-analysis of two studies showed there was low quality evidence of no difference between groups at short term for depression ( $\operatorname{SMD} 0.29,-0.16$ to $0.73, \mathrm{I}^{2}=0 \%$ ) and very low quality evidence of no difference at intermediate term based on one single study (MD 0.79, -3.25 to 4.83). For anxiety, there was no difference between groups at short term based on two studies and low quality 
evidence (SMD -0.02, -0.46 to $0.43, \mathrm{I}^{2}=0 \%$ ), and intermediate term based on a single study and very low quality evidence (MD 1.89, -2.71 to 6.49 ).

\section{DISCUSSION}

The current evidence does not indicate clinically important effects of smoking cessation programs for improving outcomes in people with chronic pain. The evidence suggests a reduction in smoking status and for the number of cigarettes consumed per day in one study; however, the effect attenuated over time. However, this is based on two studies providing very low to low quality evidence.

Smoking cessation interventions have been successfully integrated into the management of other health conditions (e.g. posttraumatic stress disorders, cardiovascular diseases), ${ }^{20,21}$ but it seems that the relationship between smoking and chronic pain may be more complex. Smoking may limit the delivery of oxygen-rich blood to bones and tissues, decreasing blood and nutrient flow, which can lead to degeneration, fatigue and slower healing, and make chronic pain conditions worse. ${ }^{14}$ However, nicotine itself has been reported as having analgesic properties. ${ }^{8,9}$ There is emerging evidence on the acute analgesic effects of nicotine through the possible activation of nicotinic acetylcholine receptors distributed through the central and peripheral nervous systems. ${ }^{9}$ Further, previous studies showed that people with chronic pain perceive smoking as a way to cope with pain and distress, and have concerns that abstinence would result in worsening of their pain. ${ }^{13,22}$ These patients also see smoking as a distraction from their pain, which can also lead to pain reduction through neurophysiologic changes in the brain. ${ }^{13,23}$ These observations make smoking cessation programs for people with chronic pain a particular clinical challenge.

This review also raises the question of whether smoking cessation programs designed for the general (smoking) public are directly transferrable to this population. It is likely that people with chronic pain face unique barriers to cessation. If so, smoking cessation interventions should be adapted to address specific barriers and meet the needs of people with chronic pain. Our review did not find any evidence for adapted cessation programs.

To our knowledge, this is the first systematic review investigating smoking cessation interventions for chronic pain. The strengths of this review include the methodological quality, due to following recommendations of the Cochrane Collaboration, and the use of the GRADE approach for assessing the quality of evidence. A limitation was that we only 
identified two small trials that included two diverse conditions. We considered pooling of the findings of these two trials appropriate because our study question concerned the issue of chronic pain, regardless of specific pathological cause. Readers can interpret the disaggregated results provided in Table 1.

Smoking cessation for patients with chronic pain remains an important clinical challenge. These patients are more likely to smoke, and smoking is suggested to influence pain and disability. Our review shows there is a paucity of evidence to conclude if smoking cessation can improve pain or disability in people with chronic pain. However, arguably reducing smoking in this population is equally important to reduce their overall chronic disease risk. More high-quality trials are needed in this area.

\section{FUNDING}

None.

\section{DECLARATION OF INTERESTS}

HL is funded by the National Health and Medical Research Council (grant no. APP1126767); receives project funding from the Berkeley Initiative for Transparency in the Social Sciences, a program of the Center for Effective Global Action (CEGA), with support from the Laura and John Arnold Foundation; and is a Catalyst for the Berkeley Initiative for Transparency in the Social Sciences. He has received consultancy funds from Cancer Council Australia.

\section{ACKNOWLEDGEMENTS}

None. 


\section{References}

1. Elzahaf RA, Tashani OA, Unsworth BA, et al. The prevalence of chronic pain with an analysis of countries with a Human Development Index less than 0.9: a systematic review without meta-analysis. Curr Med Res Opin. 2012;28(7):1221-9.

2. Global Burden of Disease Study C. Global, regional, and national incidence, prevalence, and years lived with disability for 301 acute and chronic diseases and injuries in 188 countries, 1990-2013: a systematic analysis for the Global Burden of Disease Study 2013. Lancet. 2015;386(9995):743-800.

3. Brooks PM. The burden of musculoskeletal disease--a global perspective. Clin Rheumatol. 2006;25(6):778-81.

4. Shiri R, Karppinen J, Leino-Arjas P, et al. The association between smoking and low back pain: a meta-analysis. Am J Med. 2010;123(1):87.e7-35.

5. Criswell LA, Merlino LA, Cerhan JR, et al. Cigarette smoking and the risk of rheumatoid arthritis among postmenopausal women: results from the Iowa Women's Health Study. Am J Med. 2002;112(6):465-71.

6. Shiri R, Falah-Hassani K. The Effect of Smoking on the Risk of Sciatica: A Metaanalysis. Am J Med. 2016;129(1):64-73 e20.

7. Ditre JW, Brandon TH, Zale EL, et al. Pain, nicotine, and smoking: research findings and mechanistic considerations. Psychol Bull. 2011;137(6):1065-93.

8. D' Silva J, Devadiga S, Dengody P, et al. Smoking and chronic pain. J Health Res Rev. 2014;1(2):34-9.

9. Ditre J, Heckman B, Zale E, et al. Acute analgesic effects of nicotine and tobacco in humans: a meta-analysis. Pain. 2016;157(7):1373-81.

10. Fishbain DA, Lewis JE, Cole B, et al. Variables associated with current smoking status in chronic pain patients. Pain Med. 2007;8(4):301-11. 
11. Fishbain DA, Lewis JE, Cutler R, et al. Does smoking status affect multidisciplinary pain facility treatment outcome? Pain Med. 2008;9(8):1081-90.

12. Vogt MT, Hanscom B, Lauerman WC, et al. Influence of smoking on the health status of spinal patients: the National Spine Network database. Spine (Phila Pa 1976). 2002;27(3):313-9.

13. Hooten WM, Vickers KS, Shi Y, et al. Smoking cessation and chronic pain: patient and pain medicine physician attitudes. Pain Pract. 2011;11(6):552-63.

14. Shi Y, Weingarten TN, Mantilla CB, et al. Smoking and pain: pathophysiology and clinical implications. Anesthesiology. 2010;113(4):977-92.

15. Liberati A, Altman DG, Tetzlaff $\mathrm{J}$, et al. The PRISMA statement for reporting systematic reviews and meta-analyses of studies that evaluate healthcare interventions: explanation and elaboration. BMJ. 2009;339:b2700.

16. Furlan AD, Malmivaara A, Chou R, et al. 2015 Updated Method Guideline for Systematic Reviews in the Cochrane Back and Neck Group. Spine (Phila Pa 1976). 2015.

17. Saragiotto BT, Maher CG, Yamato TP, et al. Motor control exercise for chronic nonspecific low-back pain. Cochrane Database Syst Rev. 2016;1:CD012004.

18. Aimer P, Treharne GJ, Stebbings S, et al. Efficacy of a Rheumatoid Arthritis-Specific Smoking Cessation Program: A Randomized Controlled Pilot Trial. Arthritis Care Res (Hoboken). 2017;69(1):28-37.

19. Hooten WM, Townsend CO, Hays JT, et al. A cognitive behavioral smoking abstinence intervention for adults with chronic pain: a randomized controlled pilot trial. Addict Behav. 2014;39(3):593-9.

20. McFall M, Saxon AJ, Malte CA, et al. Integrating tobacco cessation into mental health care for posttraumatic stress disorder: a randomized controlled trial. JAMA. 2010;304(22):2485-93. 
21. Hall SM, Tsoh JY, Prochaska JJ, et al. Treatment for cigarette smoking among depressed mental health outpatients: a randomized clinical trial. Am J Public Health. 2006;96(10):1808-14.

22. Chapman SL, Wu LT. Associations between cigarette smoking and pain among veterans. Epidemiol Rev. 2015;37:86-102.

23. Bantick SJ, Wise RG, Ploghaus A, et al. Imaging how attention modulates pain in humans using functional MRI. Brain. 2002;125(Pt 2):310-9. 
Table 1. Characteristics of the included studies.

\begin{tabular}{|c|c|c|c|c|c|c|c|c|c|}
\hline $\begin{array}{l}\text { Author } \\
\text { (Year) }\end{array}$ & Country & Participants & $\begin{array}{l}\text { Female, } \\
\text { n (\%) }\end{array}$ & $\begin{array}{l}\text { Age, } \\
\text { mean } \\
(\mathrm{SD})\end{array}$ & $\begin{array}{l}\text { Symptom } \\
\text { duration } \\
\text { (years), } \\
\text { mean (SD) }\end{array}$ & Outcomes & Intervention & Comparison & $\begin{array}{l}\text { Main } \\
\text { results }\end{array}$ \\
\hline $\begin{array}{l}\text { Aimer } \\
2017^{18}\end{array}$ & $\begin{array}{l}\text { New } \\
\text { Zealand }\end{array}$ & $\begin{array}{l}39 \text { smokers with } \\
\text { Rheumatoid } \\
\text { Arthritis (RA) as } \\
\text { defined by the } \\
2010 \text { ACR/EULAR }\end{array}$ & $21(55 \%)$ & $56.5(11.8)$ & $7.7(8.4)$ & $\begin{array}{l}\text { Pain, smoking } \\
\text { status, cigarettes } \\
\text { consumption, } \\
\text { depression and } \\
\text { anxiety at } 3 \text { and } 6 \\
\text { months. }\end{array}$ & $\begin{array}{l}\text { 3-month tailored } \\
\text { smoking cessation } \\
\text { program (incl. barriers to } \\
\text { smoking cessation, } \\
\text { information on RA and } \\
\text { smoking, pain, exercise, } \\
\text { and coping strategies) }\end{array}$ & $\begin{array}{l}\text { Standard } \\
\text { smoking } \\
\text { cessation } \\
\text { advice }\end{array}$ & $\begin{array}{l}\text { No } \\
\text { significant } \\
\text { difference } \\
\text { in smoking } \\
\text { cessation } \\
\text { rates or } \\
\text { number of } \\
\text { cigarettes } \\
\text { smoked } \\
\text { daily } \\
\text { between } \\
\text { groups. }\end{array}$ \\
\hline $\begin{array}{l}\text { Hooten } \\
2014^{19}\end{array}$ & USA & $\begin{array}{l}60 \text { smokers with } \\
\text { chronic non-cancer } \\
\text { pain }\end{array}$ & $47(78 \%)$ & 42.7 (13.5) & $9.2(7.8)$ & $\begin{array}{l}\text { Pain (0-100 VAS), } \\
\text { function (SF-36 } \\
\text { physical function), } \\
\text { smoking status, } \\
\text { cigarettes } \\
\text { consumption, } \\
\text { depression (CES- }\end{array}$ & $\begin{array}{l}\text { 7-session cognitive } \\
\text { behavioural smoking } \\
\text { abstinence intervention } \\
\text { (incl. individual and } \\
\text { group sessions based on } \\
\text { the barriers and }\end{array}$ & $\begin{array}{l}\text { 1-hour } \\
\text { smoking } \\
\text { abstinence } \\
\text { intervention }\end{array}$ & $\begin{array}{l}\text { Statistically } \\
\text { significant } \\
\text { effect for } \\
\text { pain and } \\
\text { function for } \\
\text { the } \\
\text { intervention }\end{array}$ \\
\hline
\end{tabular}


D), anxiety (PASS- facilitators to smoking

20) at 3 weeks and

6 months. group. The

number of

cigarettes

smoked

daily

decreased.

SD: Standard deviation, VAS: Visual Analogue Scale, CES-D: Center for Epidemiologic Studies-Depression scale, PASS-20: Pain Anxiety Symptoms Scale short version. 
Table 2. Summary of findings and quality of evidence

\begin{tabular}{|c|c|c|c|c|c|}
\hline Outcome & Follow-up & $\begin{array}{l}\text { Number of } \\
\text { participants (Studies) }\end{array}$ & Effect Size (95\% CI) & $\begin{array}{l}\text { Quality of } \\
\text { Evidence } \\
\text { (GRADE) }\end{array}$ & Comments \\
\hline \multicolumn{6}{|l|}{ Primary outcomes } \\
\hline \multirow[t]{2}{*}{ Pain } & Short term & 79 (2 studies) & SMD $-0.33(-0.79$ to 0.12$)$ & Low & $\begin{array}{l}\text { The difference is not statistically } \\
\text { or clinically significant }\end{array}$ \\
\hline & Intermediate & 15 (1 study) & $\mathrm{MD}-0.27(-2.06$ to 1.52$)$ & Very low & $\begin{array}{l}\text { The difference is not statistically } \\
\text { or clinically significant }\end{array}$ \\
\hline Function & Short term & 60 (1 study) & MD $-3.30(-11.73$ to 5.13$)$ & Very low & $\begin{array}{l}\text { The difference is not statistically } \\
\text { or clinically significant }\end{array}$ \\
\hline \multicolumn{6}{|l|}{ Secondary outcomes } \\
\hline \multirow[t]{2}{*}{ Smoking cessation } & Short term & 60 (1 study) & RR 0.78 (0.60 to 1.01$)$ & Very low & $\begin{array}{l}\text { The difference is not statistically } \\
\text { or clinically significant }\end{array}$ \\
\hline & Intermediate & 98 (2 studies) & RR 0.83 (0.70 to 0.98$)$ & Low & $\begin{array}{l}\text { Statistically significant } \\
\text { difference favouring } \\
\text { intervention }\end{array}$ \\
\hline \multirow[t]{2}{*}{$\begin{array}{l}\text { Cigarette consumption } \\
\text { per day }\end{array}$} & Short term & 60 (1 study) & $\begin{array}{l}\text { MD -6.90 (-12.07 to - } \\
1.73)\end{array}$ & Very low & $\begin{array}{l}\text { Statistically significant } \\
\text { difference favouring } \\
\text { intervention }\end{array}$ \\
\hline & Intermediate & 38 (1 study) & MD $1.40(-4.28$ to 7.08$)$ & Very low & $\begin{array}{l}\text { The difference is not statistically } \\
\text { or clinically significant }\end{array}$ \\
\hline
\end{tabular}


Depression

Short term

79 (2 studies)

Intermediate

15 (1 study)

Short term

79 (2 studies)

Intermediate

15 (1 study)
SMD $0.29(-0.16$ to 0.73$)$

Low

MD $0.79(-3.25$ to 4.83$) \quad$ Very low

SMD -0.02 (-0.46 to 0.43) Low

MD 1.89 (-2.71 to 6.49$)$

Very low
The difference is not statistically or clinically significant

The difference is not statistically or clinically significant

The difference is not statistically or clinically significant

The difference is not statistically or clinically significant

SMD: Standardised Mean Difference, MD: Mean Difference, RR: Risk Ratio, CI: Confidence Interval. For outcomes pain, function, cigarettes consumption, depression, and anxiety, a negative effect size represents and effect in favour of the intervention group. 